\title{
A case of porencephaly complicated by central diabetes insipidus in a dog
}

\author{
ALI EVREN HAYDARDEDEOĞLU, EKREM ÇAĞATAY ÇOLAKOĞLU*, \\ HADI ALIHOSSEINI**
}

\begin{abstract}
Internal Medicine Service, Small Animal Teaching Hospital, Aksaray University, Aksaray, 68100, Turkey *Internal Medicine Service, Small Animal Teaching Hospital, Ankara University, Ankara, 06110, Turkey **Internal Medicine Service, Terapist Veterinary Medical Center, İstanbul, 34337, Turkey
\end{abstract}

\section{Haydardedeoğlu A. E., Çolakoğlu E. Ç., Alihosseini H. A case of porencephaly complicated by central diabetes insipidus in a dog Summary}

Porencephaly is an extremely rare congenital disorder of the central nervous system characterized by focal cerebral cysts and cavities. Central diabetes insipidus is also a well-described condition in veterinary medicine. A 4-year-old Terrier dog was referred to the hospital with polyuria and polydipsia. Based on a diagnostic examination, porencephaly complicated by central diabetes insipidus was determined. Treatment consisted in administering intranasal desmopressin to the conjunctiva. The dog remains clinically healthy for 2 years. This case report reflects the MRI features of porencephaly and central diabetes insipidus associated with congenital porencephaly.

Keywords: porencephaly, dog, diabetes insipidus

Cystic intracranial malformations have been reported in animals as a possible cause of seizure, blindness, ataxia, and other neurological signs $(6,7,16)$. However, porencephaly could be an incidental finding in asymptomatic dogs. Porencephaly is a rare congenital disorder of the central nervous system characterized by cysts and cavities containing CSF $(3,4,13)$, usually connecting the ventricles. Porencephaly in human medicine is considered secondary to environmental factors (toxins, infections), vascular cerebral changes caused by trauma, and hypoxic or congenital defects during the fetal period $(16,17)$. There are sporadic reports of porencephaly in dogs $(3,8,13)$.

Central diabetes insipidus characterized by the inability to concentrate the urine is a well-defined condition in veterinary medicine (18). Etiology of central diabetes insipidus includes obstruction or infiltration of the pituitary gland by tumors, injury, trauma, or infections $(2,18)$. To the best of the authors' knowledge, this is the first report in veterinary literature concerning a case of porencephaly complicated by central diabetes insipidus. The aim of this case report was to describe the MRI features of porencephaly lesions and to describe the central diabetes insipidus associated with congenital porencephaly.

\section{Case history}

A 4-year-old neutered male Terrier dog weighing $3.6 \mathrm{~kg}$ was referred to the Veterinary Teaching Hospital of Veterinary Faculty, Ankara University with a history of polyuria and polydipsia for 6 months. Physical observations during hospitalization confirmed polyuria and polydipsia with a water intake of $160 \mathrm{ml} / \mathrm{kg} / \mathrm{day}$. The initial blood analyses, including complete blood count and serum profiles, are shown in Table 1. Urinalysis revealed hyposthenuria (urine specific gravity 1.005). Urine osmolality was $245 \mathrm{mOsm} / \mathrm{kg}$ (reference interval $<300$ ), and the calculated plasma osmolality was $310 \mathrm{mOsm} / \mathrm{kg}$ (reference interval $>300$ ). Urine specific gravity, urine osmolality, and plasma osmolality obained in a post-water deprivation test were $1.005,250 \mathrm{mOsm} / \mathrm{kg}$, and $340 \mathrm{mOsm} / \mathrm{kg}$, respectively. No remarkable changes were also observed in abdominal radiography, ultrasonography, or urine culture to differentiate the underlying infectious and metabolic diseases, including adrenal disorders and hypothyroidism. Brain MRI revealed (Fig. 1) right fronto-parietal cystic and cavitary lesions with ex vacuo changes. CSF cytology and culture revealed no remarkable changes. Treatment consisted in applying intranasal desmopressin to the conjunctiva ( 2 drops in one eye, q $12 \mathrm{hr}$ ). Water intake decreased significantly to $90 \mathrm{ml} /$ $\mathrm{kg} /$ day. Urine specific gravity showed an increase in the isosthenuric range (1.015). A desmopressin response test 
was consistent with central diabetes insipidus. A follow up brain MRI was performed 6 months later, and the lesion was found to be stable. The final diagnosis was porencephaly complicated by central diabetes insipidus. The dog remains clinically healthy 2 years later with desmopressin treatment.

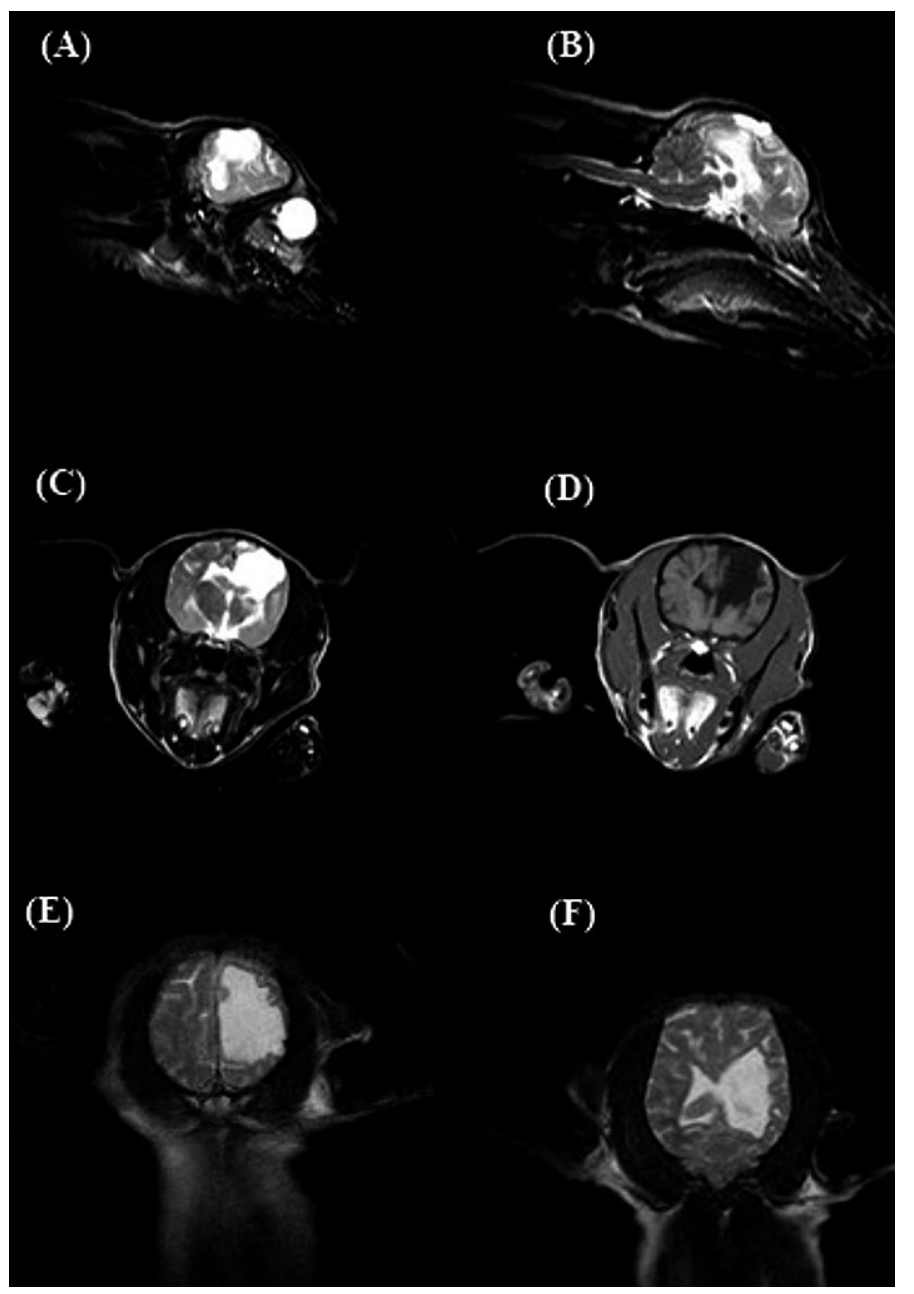

\section{Discussion}

Porencephaly is a rare cerebral malformation involving cerebral cavities or cysts filled with CSF and connecting the ventricular network and brain surface (7). The condition of focal areas of the cerebrum without residual parenchyma may be described as porencephaly. Neurological signs including seizure have been reported in animals with hydrocephaly, lissencephaly, and porencephaly. However, porencephaly could be an incidental finding in dogs without any symptoms $(3,14)$. Clinical signs may be absent at birth and may not begin for many years (10). Although epileptic seizure resulting from congenital brain malformations is the most common sign in dogs (15), the case presented here did not show any remarkable clinical signs, including neurological symptoms, for many years. Environmental factors and acquired or perinatal vascular cerebral lesions associated with trauma, viral infections, congenital defects, or inheritance are the possible etiology of porencephaly $(5,12,17)$. In this case, no data obtained by anamnesis or diagnostic examination showed a distinct acquired etiology.

Fig. 1. MRI images showing cystic and cavitary lesions affecting the dog with porencephaly. A, B - T2 images show a normal size and configuration of the $4^{\text {th }}$ ventricle. No significant signal changes were detected in the brainstem and cerebellum. C, D - No central line deviation is obvious. The cavities are pervaded by thin lines of residual brain tissue. A, B, C, D, E, F - Partial loss of the right-parietal region. Signal changes and cavitations in the right fronto-parietal region connected to the right lateral ventricle, causing enlargement in the lateral ventricle (ex vacuo changes) and the right hemispheric sulcus. Isointense encephalomalacic areas with CSF causing volume loss in all sequences.

Tab. 1. Blood analyses in the dog

\begin{tabular}{|c|c|c|c|c|c|}
\hline CBC & Results & References & Serum Profiles & Results & References \\
\hline Leukocyte $\left(10^{9} / I\right)$ & 10.32 & $6-17$ & Glucose (g/dl) & 104 & $65-118$ \\
\hline Lymphocyte (109/I) & 2.36 & $0.9-5$ & Urea (mg/dl) & 42 & $15-59$ \\
\hline Monocyte $\left(10^{9} / \mathrm{l}\right)$ & 0.66 & $0.2-1.5$ & Creatinin (mg/dl) & 1.2 & $0.5-1.5$ \\
\hline Neutrophil $\left(10^{9} / I\right)$ & 7.29 & $3.5-12$ & Total Protein (g/dl) & 4.5 & $5.4-7.8$ \\
\hline Eosinophil $\left(10^{9} / I\right)$ & 0.1 & $0.1-2.5$ & Albumin $(g / d l)$ & 2.7 & 2.8-4 \\
\hline Erythrocyte $\left(10^{12} / \mathrm{l}\right)$ & 9.18 & $5.5-8.5$ & Total Bilirubin (mg/dl) & 0.1 & $0.1-0.3$ \\
\hline Hemoglobin ( $\mathrm{g} / \mathrm{dl})$ & 18.4 & $12-18$ & Direct Bilirubin (mg/dl) & 0.06 & - \\
\hline Hematocrit (\%) & 53.33 & $37-50$ & Alkaline Phosphatase (IU/L) & 15 & $<130$ \\
\hline Mean Corpuscular Volume (fl) & 61 & $60-72$ & Alanine Transaminase(IU/L) & 45 & $<50$ \\
\hline Mean Corpuscular Hemoglobin (pg) & 19 & $18-125.5$ & Aspartate transaminase (IU/L) & 24 & $<40$ \\
\hline Mean Corpuscular Hemoglobin Concentration (g/dl) & 32.7 & $32-38.5$ & Gamma-Glutamyl Transferase (IU/L) & 6 & $6-28$ \\
\hline Erythrocyte Distribution Width (\%) & 16.3 & 12-17.5 & Chlorine (mg/dl) & 94 & $102-117$ \\
\hline Platelets $\left(10^{9} / I\right)$ & 471 & $200-500$ & Sodium (mmol/l) & 138 & $147-156$ \\
\hline \multirow{4}{*}{ Mean Platelet Volume (fl) } & 9.9 & $5.5-10.5$ & Potassium (mmol/l) & 4.9 & $3.6-5.6$ \\
\hline & & & Calcium (mg/dl) & 9.8 & $9-11.3$ \\
\hline & & & Total Thyroxine $(\mu \mathrm{g} / \mathrm{dl})$ & 2.34 & $0.6-3.6$ \\
\hline & & & Cortisol (mg/dl) & 2.68 & $1-4$ \\
\hline
\end{tabular}


Unlike hydranencephaly, defects in porencephaly are less extensive and limited to the cerebrum (9). Due to the absence of active neoplastic or inflammatory causes on a followup brain MRI, the focal cavitary lesions in the case were defined as porencephaly. It has been reported that central diabetes insipidus may occur as a result of pituitary injury, including trauma, infection, inflammation, and disruption of blood supply (2). It has also been reported that destructive mechanisms causing the development of hydranencephaly may also lead to damage in neurohypophysis, causing central diabetes insipidus (11). The etiology of central diabetes insipidus is described as idiopathic in the absence of structural hypothalamic and pituitary defects. Although it may not be possible to detect structural hypothalamic and pituitary defects on imaging, an underlying unknown pathology may be the cause of central diabetes insipidus (1). The absence of pituitary or hypothalamic lesions on MRI in the dog with porencephaly increased the probability of an unknown pathology between porencephaly and diabetes insipidus.

In conclusion, the association between porencephaly and central diabetes insipidus should prompt clinicians to remain vigilant about the development of central diabetes insipidus in dogs without detectable hypothalamic or pituitary abnormalities on MRI.

\section{References}

1. Baylis $P$. H.: Understanding the cause of idiopathic cranial diabetes insipidus: a step forward. Clin. Endocrinol. 1994, 40, 171-172.

2. Dabrowski E., Kadakia R., Zimmerman D.: Diabetes insipidusin infants and children. Best Pract. Res. Clin. Endocrinol. Metab. 2016, 30, 317-328.

3.Davies E. S. S., Volk H. A., Behr S., Summers B., de Lahunta A., Syme H., Jull P., Garosi L.: Porencephaly and hydranencephaly in six dogs. Vet. Rec. 2012, 170, 179 .
4. Gould D. B., Phalan F. C., Breedveld G. J., van Mil S. E., Smith R. S., Schimenti J. C., Aguglia U., van der Knaap M. S., Heutink P., John S. W.: Mutations in Col4a1 cause 134 perinatal cerebral hemorrhage and porencephaly. Science 2005, 308, 1167-1171.

5. Hewicker-Trautwein M., Liess B., Trautwein G.: Brain lesions in calves following transplacental infection with bovine-virus diarrhea virus. Zentralbl. Veterinarmed. B 1995, 42, 65-77.

6. Hori A., Hanazono K., Miyoshi K.: Porencephaly in dogs and cats: relationships between magnetic resonance imaging (MRI) features and hippocampal atrophy. J. Vet. Med. Sci. 2015, 77, 889-892.

7. Machado G. F.: Porencephaly and cortical dysplasia as cause of seizures in a dog. BMC Vet. Res. 2012, 8, 1-6.

8. Mackillop E.: Magnetic resonance imaging of intracranial malformations in dogs and cats. Vet. Radiol. Ultrasound 2011, 52, 42-51.

9. Maxie G. M. Sameh $Y$ : Malformations of the central nervous system, [in:] Maxie G. M. (ed.): Jubb, Kenedy, and Palmer's Pathology of Domestic Animals. $5^{\text {th }}$ ed., Saunders Elsevier, Amsterdam 2007, p. 298-321.

10. Naef R.: Clinical features of porencephaly: a review of thirty-two cases. AMA Archives of Neurology and Psychiatry 1958, 80, 133-147.

11. Omar A. T., Kathleen J. O.: Hydranencephaly complicated by central diabetes insipidus: report of two cases and systematic review of literature. Child's Nervous System 2019, 35, 1165-1171.

12. Richardson C., Taylor W. P., Terlecki S., Gibbs E. P.: Observations on transplacental infection with bluetongue virus in sheep. Am. J. Vet. Res. 1985, 46, 1912-1922.

13. Schmidt M. J., Klumpp S., Amort K., Jawinski S., Kramer M.: Porencephaly in dogs and cats: magnetic resonance imaging findings and clinical signs. Vet. Radiol. Ultrasound 2012, 53, 142-149.

14. Summers B. A., Cummings J. F., de Lahunta A (ed.): Veterinary neuropathology, St. Louis, M. Mosby 1995.

15. Thomas W. B.: Idiopathic epilepsy in dogs and cats. Vet. Clin. North Am. Small Anim. Pract. 2010, 40, 161-179.

16. Tominaga I., Kaïhou M., Kimura T., Onaya M., Kashima H., Kato Y. Tamagawa K.: Cytomegalovirus fetal infection. Porencephaly with polymicrogyria in a 15-year-old boy. Rev. Neurol. 1996, 152, 479-482.

17. Tonni G., Ferrari B., Defelice C., Gentini G.: Neonatal porencephaly in very low birth weight infants: Ultrasound timing of asphyxial injury and neurodevelopmental outcome at two years of age. J. Matern. Fetal Neonatal. Med. 2005, 18, 361-365

18. Verbalis $J$. G.: Acquired Forms of Central Diabetes Insipidus: Mechanisms of Disease. Best Pract. Res. Clin. Endocrinol. Metab. 2020, 101.

Corresponding author: Assoc. Prof. Ekrem Çağatay Çolakoğlu, Ankara University, Faculty of Veterinary Medicine, Department of Internal Medicine, Ankara, Turkey; e-mail: colakoglu@ankara.edu.tr 